\title{
Prevalência de adultos infectados por Leishmania leishmania chagasi entre doadores de sangue do Hemocentro Regional de Montes Claros, Minas Gerais, Brasil
}

\author{
Prevalence of adults infected with Leishmania (Leishmania) chagasi among blood donors of the \\ Hemominas Foundation in Montes Claros, Brazil
}

Elaine V.R. Urias ${ }^{1}$

Silvio F. G. Carvalho

Cláudia L. Oliveira ${ }^{3}$

Maria de Lourdes M. Carvalho ${ }^{4}$

Leandro F. Teles 5

Murilo C. Rodrigues ${ }^{6}$

Caroline N. Maia
O objetivo deste trabalho foi estudar a prevalência de adultos infectados por $L$. L. chagasi entre doadores de sangue do Hemocentro Regional de Montes Claros/MG .Realizou-se estudo epidemiológico, transversal e quantitativo, no periodo de 16/09/08 a 13/11/08. Participaram da pesquisa 421 doadores aptos na triagem clínica, sendo realizada imunofluorescência indireta para L.L.chagasi. Aqueles que apresentaram resultados positivos foram submetidos ao teste rápido antígeno-específico para Leishmania donovani. A análise das variáveis gênero, faixa etária, procedência, número de doações, resultados sorológicos para leishmaniose e chagas, foi realizada pelos testes estatísticos qui-quadrado (x2), x2 com tendência linear e teste Fisher. Foi considerado o nivel de significância de $5 \%(p<0,05)$. O perfil da amostra foi semelhante ao perfil geral dos doadores. Os participantes, em sua maioria procedentes da zona urbana (92,7\%), residentes em Montes Claros (67,9\%), homens (61,3\%), com faixa etária de 18 a 29 anos. Em relação aos resultados sorológicos, 23 (5,5\%) apresentaram positividade para imunofluorescência indireta e nenhum destes foi positivo no teste rápido. Ao comparar os resultados da imunofluorescência para leishmaniose e a sorologia Elisa chagas, dois foram positivos para ambos os testes, sendo demonstrada correlação estatística significante $(p=0,003)$. Porém, 21 foram positivos para leishmaniose e negativos para chagas. Os resultados permitiram conhecer a prevalência da infecção por L. l. chagasi em indivíduos assintomáticos, adultos, doadores de sangue do Hemocentro Regional de Montes Claros/MG e apontam para a necessidade de maiores estudos quanto ao possivel risco de transmissão transfusional da doença. Rev. Bras. Hematol. Hemoter.

Palavras-chave: Leishmaniose visceral; doadores de sangue; assintomáticos.

\footnotetext{
${ }^{\prime}$ Médica Hematologista/ Hemoterapeuta. Gerente técnica do Hemocentro Regional de Montes Claros/MG e Professora Assistente da Universidade Estadual de Montes Claros (Unimontes)-MG.

${ }^{2}$ Médico. Coordenador do Serviço de Doenças Infecciosas e Parasitárias da Universidade Estadual de Montes Claros-MG.

${ }^{3}$ Médica Epidemiologista da Fundação Hemominas.

${ }^{4}$ Farmacêutica Bioquímica. Coordenadora do Núcleo de Qualidade do Hemocentro Regional de Montes Claros-MG.

${ }_{6}^{5}$ Farmacêutico Bioquímico do Hemocentro Regional de Montes Claros e Universidade Estadual de Montes Claros-MG.

Farmacêutico Bioquímico do Laboratório Macro Regional de Saúde Pública GRS/ Montes Claros-MG.

${ }^{7}$ Farmacêutico Bioquímico do Hemocentro Regional de Montes Claros-MG.
}

Correspondência: Elaine Veloso Rocha Urias Rua Urbino Viana, 640 - Vila Guilhermina 39400-087- Montes Claros-MG - Brasil

Fonelfax: (55 38) 3212-7800

E-mail:moc.gtecnica@hemominas.mg.gov.br

Doi: 


\section{Introdução}

A leishmaniose visceral (LV) é apontada como doença de alta incidência, ampla distribuição, em expansão e com característica de urbanização atingindo grandes centros. Nos últimos vinte anos, em várias cidades brasileiras, no Nordeste (São Luis, Natal, Aracaju), Norte (Boa Vista e Santarém), Sudeste (Belo Horizonte e Montes Claros) e Centro Oeste (Cuiabá e Campo Grande) têm sido registradas epidemias de LV. ${ }^{1}$ Devido à grande expansão geográfica, aumento do número de casos no cenário mundial, a gravidade da doença e o pouco interesse da grande indústria farmacêutica em desenvolver pesquisas na área, a leishmaniose visceral tem sido considerada pela Organização Mundial de Saúde como uma doença negligenciável, o que a coloca na situação de doença a ser priorizada pelos governos locais. ${ }^{2,3}$ Atualmente 65 países têm casos registrados e esta doença acomete todos os continentes, exceto a Oceania. ${ }^{1,4}$

A leishmaniose visceral ou calazar é transmitida ao homem pela picada da fêmea do mosquito flebotomíneo Lutzomyia longipalpis infectado pela Leishmania leishmania chagasi, forma encontrada no Brasil., ${ }^{5,6}$ As manifestações clínicas da doença podem variar de formas oligossintomáticas a graves. A resposta imunológica do homem à infecção ainda não está claramente definida. ${ }^{7,8} \mathrm{ALV}$ se caracteriza por febre, hepatoesplenomegalia, palidez, pancitopenia, hipergamaglobulinemia e hipoalbuminemia, sendo frequentes complicações infecciosas e hemorrágicas. ${ }^{9}$

O programa de controle da LV no Brasil baseia-se atualmente em três estratégias básicas: detecção e tratamento dos casos humanos, controle dos reservatórios domésticos e controle dos vetores. ${ }^{10,11}$ A transmissão através de transfusão sanguínea, embora possível do ponto de vista teórico, ainda não possui comprovação científica consistente. ${ }^{12-17} \mathrm{~A}$ legislação brasileira de hemoterapia, RDC n ${ }^{\circ} 153$ de 2004, preconiza como rotina nos bancos de sangue testes sorológicos para chagas, hepatites B e C, sífilis, HTLV 1 e 2, HIV 1 e 2 , não sendo recomendada sorologia para LV. ${ }^{17}$ São notificados, em média, 3.374 novos casos por ano em nosso país e a incidência é de dois casos a cada 100 mil habitantes. ${ }^{18} \mathrm{~A}$ região Nordeste é responsável pela grande maioria dos casos $(52,9 \%)$, destacando-se o Maranhão como primeiro estado de maior frequência, e a região Sudeste representa $18,5 \%$ dos casos notificados. Segundo dados do Sistema de Informação de Agravos de Notificação (Sinan), em 2008 foram notificados 399 casos no estado de Minas Gerais (Figura 1), demonstrando segundo maior registro do País. ${ }^{19}$

Testes sorológicos para leishmaniose visceral apresentam boa sensibilidade. No Brasil, os mais utilizados são a imunofluorescência indireta (RIFI), considerada reagente quando apresenta títulos iguais ou superiores a 1:80, e ELISA. ${ }^{18}$ A RIFI expressa os níveis de anticorpos circulantes apresentando sensibilidade de $84,61 \%$ até $100 \%$ e especificidade de $82,9 \% .{ }^{20}$ Estudo recente em quatro regiões do Brasil (MA, PI, BA, MG) demonstrou sensibilidade de $88 \%$ e especificidade de $81 \% .{ }^{21}$ Uma das principais limitações da técnica é a ocorrência de reações cruzadas com leishmaniose tegumentar, chagas, malária, esquistossomose e tuberculose pulmonar. $^{22} \mathrm{O}$ teste rápido antígeno-específico para Leishmania donovani (Kalazar detect $\left.{ }^{\circledR}\right)$ apresenta sensibilidade de 67\% (Sudão) a 100\% (Índia). Diferenças na resposta imunológica em grupos distintos podem explicar

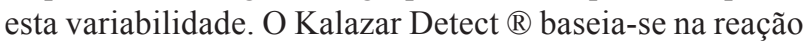
do soro ou sangue do paciente com o antígeno K39 fixado em papel. Pode apresentar reação cruzada com malária, febre tifoide e tuberculose. Trata-se de teste de fácil execução e interpretação, agilizando os resultados. ${ }^{2}$ Estudo relizado em Montes Claros/MG demonstrou $90 \%$ de sensibilidade e $100 \%$ de especificidade do teste Kalazar detect ${ }^{\circledR}$ em indivíduos doentes. Achado confirmado por estudo com o

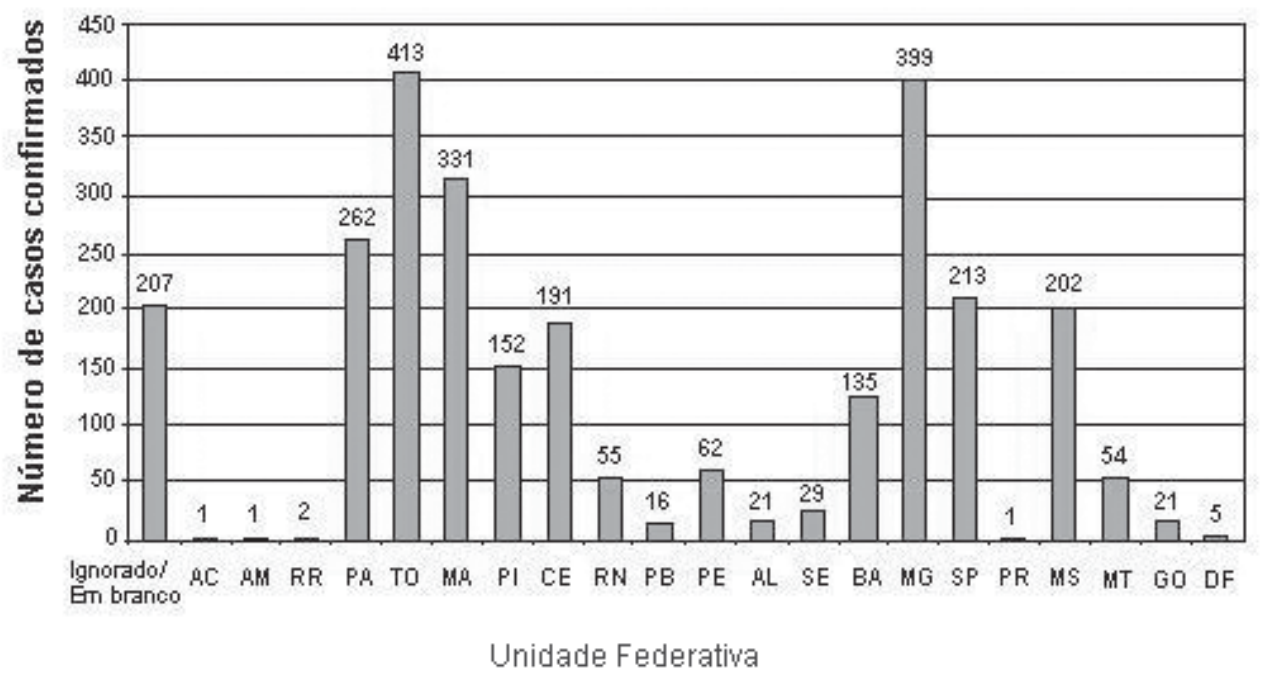

Figura 1. Casos de leishmaniose visceral confirmados por notificação no ano de 2008 por unidade federativa. Fonte: Sinan, 2009. 


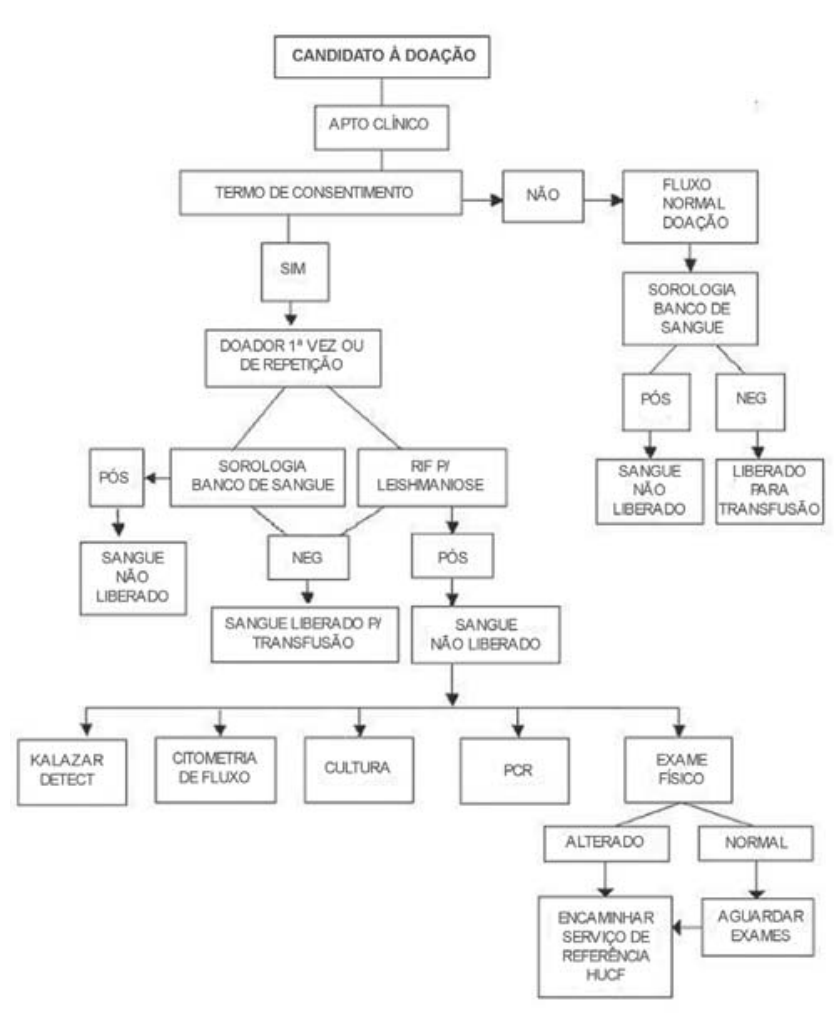

Figura 2. Fluxograma da pesquisa LV

teste rápido IT-LEISH ${ }^{\circledR}$ que apresentou sensibilidade de 93\% e especificidade de $97 \% .{ }^{21} \mathrm{O}$ objetivo deste estudo foi verificar a prevalência de adultos infectados por Leishmania leishmania chagasi entre os doadores de sangue do Hemocentro Regional de Montes Claros, área endêmica de LV. Em relação aos resultados sorológicos, 5,5\% dos participantes apresentaram sorologia positiva para LV, mas nenhum deles foi positivo no Kalazar Detect巴).

\section{Casuística e Método}

Foi realizado estudo epidemiológico do tipo transversal com abordagem quantitativa, no período de 16 de setembro a 13 de novembro de 2008, no Hemocentro Regional de Montes Claros, em doadores de sangue considerados aptos clínicos segundo a RDC n ${ }^{\circ} 153$ (Figura 2). Calculou-se uma amostra considerando prevalência estimada de LV de 3\%, erro amostral (precisão) de 1,5\% e nível de confiança igual a 95\%, obtendose um tamanho amostral de 400 indivíduos para população aproximada de 2 mil candidatos a doação/mês. Participaram da pesquisa 421 indivíduos, sendo coletada amostra de $10 \mathrm{~mL}$ de sangue para realização dos testes sorológicos. Realizou-se triagem sorológica para LV dos doadores pelo método de imunofluorescência indireta para Leishmania (Biomanguinhos), sendo considerados positivos resultados com titulação igual ou maior que 1:40. As amostras positivas na RIFI foram submetidos ao Kalazar Detect TM Rapid Test
(Inbios International), e as bolsas de sangue destes doadores não foram liberadas para transfusão. O teste imunofluorescência indireta para Leishmania foi realizado no Laboratório Macro Regional de Saúde Pública GRS/Montes Claros e o Kalazar detect ${ }^{\circledR}$ foi realizado no Hemocentro Regional de Montes Claros. Foi estabelecido como contrarreferência o Hospital Universitário Clemente Farias (HUCF) para atendimento dos casos positivos que se apresentassem qualquer sintoma clínico. Porém, todos apresentaram-se assintomáticos na avaliação clínica e serão acompanhados durante um ano.

Este trabalho faz parte de um projeto maior intilutado Transmissão da L.L. chagasi por transfusão sanguínea: um estudo do potencial de risco transfusional. Encontram-se em andamento: cultura para leishmania e citometria de fluxo no Instituto René Rachou/MG e PCR na Fundação PróSangue/SP.

\section{Resultados}

No período em que foi realizado o estudo, 1.789 candidatos se apresentaram para doar sangue. Destes, 1.178 foram aptos na triagem clínica. Obtivemos uma amostra de 421 indivíduos que participaram da pesquisa, sendo que 23 (5,5\%) apresentaram RIFI positiva para L.l.chagasi.

Podemos considerar que o perfil dos participantes não difere do perfil geral dos doadores de sangue do Hemocentro Regional de Montes Claros quanto ao gênero, faixa etária e procedência (Tabelas 1 e 2). Os participantes foram, em sua maioria, moradores da cidade de Montes Claros/MG $(67,9 \%)$, procedentes da zona urbana $(92,7 \%)$, homens $(61,3 \%)$, com

Tabela 1. Perfil geral dos doadores de sangue do Hemocentro Regional de Montes Claros, 2008

\begin{tabular}{lc}
\hline \multicolumn{1}{c}{ Variável } & Porcentagem \\
\hline Procedência & \\
Montes Claros & $89,40 \%$ \\
Outros municipios & $11,60 \%$ \\
Total & $100 \%$ \\
Região & \\
Urbana & \\
Rural & $97 \%$ \\
Gênero & $3 \%$ \\
Masculino & \\
Feminino & \\
Total & $57,90 \%$ \\
Faixa etária & $42,10 \%$ \\
18 a 29 anos & $100 \%$ \\
$>29$ anos & \\
Número de doações & $55,80 \%$ \\
01 & $44,20 \%$ \\
02 a 10 & \\
Total & $30,00 \%$ \\
\hline
\end{tabular}


faixa etária de 18 a 29 anos (53\%) e com número de doações de 2 a $10(48 \%)$.

Em relação aos resultados sorológicos, 5,5\% dos participantes apresentaram sorologia positiva para LV, mas nenhum deles foi positivo no Kalazar detect ${ }^{\circledR}$ (Tabela 3 ).

Ao comparar a sorologia positiva para LV e os resultados sorológicos para Chagas (ELISA), foi observado que

Tabela 2. Perfil geral dos participantes do estudo Hemocentro Regional de Montes Claros, 2008

\begin{tabular}{lcc}
\multicolumn{1}{c}{ Variável } & Porcentagem & RIFI positiva \\
\hline Procedência* & & \\
Montes Claros & $67,9 \%$ & $15(65,2 \%)$ \\
Outros municipios & $32,1 \%$ & $8(34,8 \%)$ \\
Total & $100 \%$ & $23(100 \%)$ \\
Região ** & & \\
Urbana & $92,7 \%$ & $23(100 \%)$ \\
Rural & $7,3 \%$ & 0 \\
Total & $100 \%$ & $23(100 \%)$ \\
Gênero *** & & \\
Masculino & $61,3 \%$ & $11(47,8 \%)$ \\
Feminino & $38,7 \%$ & $12(52,2 \%)$ \\
Total & $100 \%$ & $23(100 \%)$ \\
Faixa etária **** & & $11(47,8 \%)$ \\
18 a 29 anos & $53 \%$ & $12(52,2 \%)$ \\
$>29$ anos & $47 \%$ & $23(100 \%)$ \\
Total & $100 \%$ & \\
Número de doações **** & & $5(21,7 \%)$ \\
01 & $36 \%$ & $14(20,9 \%)$ \\
2 a 10 & $48 \%$ & $23(100 \%)$ \\
$>10$ & $16 \%$ & \\
Total & $100 \%$ & \\
\hline$*$ & &
\end{tabular}

* $\chi 2=0,082 ;$ valor $-p=0,774$

${ }^{* *} p=0,390$ (teste exato de Fisher)

*** $\chi 2=1,86$; valor $-p=0,173$

$\star \star \star \star \star * 2=0258 ;$ valor $-p=0,611$

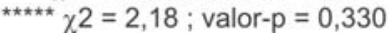

Tabela 3. Descrição dos participantes do estudo segundo resultados da sorologia,

Hemocentro Regional de Montes Claros, 2008

\begin{tabular}{lccc}
\hline \multicolumn{1}{c}{ Sorologia } & $\begin{array}{c}\mathrm{N}^{\circ} \text { de } \\
\text { participantes }\end{array}$ & $\begin{array}{c}\text { Kalazar detect } \\
\text { positico }\end{array}$ & $\begin{array}{c}\text { Kalazar detect } \\
\text { negativo }\end{array}$ \\
\hline RIFI positivo & $23(5,5 \%)$ & 0 & 23 \\
RIFI negativo & $398(94,5 \%)$ & - & 0 \\
Total & 421 & 0 & 23 \\
\hline
\end{tabular}

Tabela 4. Comparação entre a sorologia para Chagas e RIFI para LV, Hemocentro Regional de Montes Claros, 2008

\begin{tabular}{lccc}
\hline \multicolumn{4}{c}{ LV (RIFI) } \\
\hline Chagas (Elisa) & Negativo & Positivo & Total \\
\hline Negativa & 398 & $21(91,3 \%)$ & $419(99,5 \%)$ \\
Positiva & 0 & $2(8,7 \%)$ & $2(0,5 \%)$ \\
Total & $398(100 \%)$ & $23(100 \%)$ & $421(100 \%)$ \\
\hline
\end{tabular}

Valor $p=0,003$ (teste exato de Fisher)
Tabela 5. Comparação entre a sorologia para Chagas e titulação RIFI para L.V., Hemocentro Regional de Montes Claros, 2008

\begin{tabular}{lccc}
\hline \multirow{2}{*}{ LV (RIFI Positivo) } & \multicolumn{3}{c}{ Chagas } \\
\cline { 2 - 4 } & Negativo & Positivo & Total \\
\hline $1: 40$ & $20(95,2 \%)$ & 0 & $20(87 \%)$ \\
$1: 80$ & $01(4,8 \%)$ & $01(50 \%)$ & $02(8,7 \%)$ \\
$1: 160$ & 0 & $01(50 \%)$ & $01(4,3 \%)$ \\
Total & $21(100 \%)$ & $02(100 \%)$ & $23(100 \%)$ \\
\hline
\end{tabular}

apenas dois candidatos foram positivos em ambos os exames. Os demais (21 participantes) foram negativos para Chagas e positivos para LV (Tabela 4). Observou-se ainda que os dois que foram positivos em ambos os exames apresentaram titulação 1:80 e 1:160 para LV (Tabela 5).

\section{Discussão}

As doenças transmissíveis por transfusão relacionamse a infecções que podem se tornar crônicas e levar os indivíduos infectados a um estado de portadores assintomáticos. Assim, os serviços de hemoterapia precisam adotar um conjunto de medidas preventivas de segurança, como educação da população sobre o ato de doar sangue, realização de triagem clínica e epidemiológica dos candidatos a doadores, realização de exames laboratoriais que visem à redução do risco de transmissão de doenças. ${ }^{23} \mathrm{O}$ conhecimento da existência de janela imunológica (tempo entre o contato com o agente infeccioso e o desenvolvimento de anticorpos em níveis detectáveis nos testes sorológicos) deve ser sempre esclarecido, com o fim de coibir a doação de sangue de pessoas que porventura busquem, indevidamente, resultados de exames sorológicos para situações de risco. Outra consideração importante é o fato de que os testes utilizados para triagem de doadores possuem alta sensibilidade, ${ }^{17}$ produzindo, muitas vezes, resultados falsos positivos, não sendo, portanto, realizados com finalidade de diagnóstico de doenças e, sim, como método de triagem e proteção ao receptor.

No Brasil, são efetuadas anualmente cerca de 3 milhões de doações de sangue, sendo ainda frequentes problemas de desabastecimento. ${ }^{23}$ De acordo com a OMS, para um país manter os estoques de sangue e derivados regularizados, é ideal que $2,5 \%$ da população seja doadora de sangue. Todavia, o percentual de doadores brasileiros é de apenas 1,7\% por ano, segundo dados da Agência Nacional de Vigilância Sanitária (Anvisa). Vale ainda ressaltar que temos em nosso país uma demanda reprimida de procedimentos de alta complexidade, que, se corrigida, levaria a um consumo ainda maior de sangue.

A indicação adequada dos hemocomponentes ${ }^{24,25,26} \mathrm{e}$ o conhecimento das possíveis alternativas que possam evitar exposição ao sangue são medidas prioritárias que visam reduzir os riscos relacionados à prática transfusional. 
Apesar dos avanços tecnológicos na busca de substitutos do sangue humano, ainda não existem produtos que o substituam por completo. A qualidade intrínseca, segurança, durabilidade, eficácia, fácil obtenção e produção têm sido perseguidas em várias pesquisas. Porém, no momento, os esforços devem ser concentrados na criação de pool de doadores estáveis (menor risco de janela imunológica), no aprimoramento de técnicas para seleção de doadores que envolvem triagem clínica e sorológica, no uso do sangue autólogo sempre que possível e, ainda, na indicação precisa dos vários componentes sanguíneos. ${ }^{23}$

Evitar o risco de doenças infecciosas transmissíveis pelo sangue é um desafio constante para os serviços de hemoterapia. Vários patógenos (citomegalovírus, EpsteinBarr, parvovírus B19) não pesquisados nas rotinas dos bancos de sangue, ${ }^{27}$ além de doenças emergentes (gripe aviária, virose do Oeste do Nilo, forma variante da doença de Creutzfeldt-Jacob) que poderiam afetar os receptores ou o aporte de doadores, precisam ser pesquisados quanto ao risco e impacto na segurança transfusional e, se necessário, considerados nas estratégias da política do sangue do País. ${ }^{28}$

A leishmaniose visceral compõe este grupo de doenças em que o potencial de transmissão transfusional e sua relevância ainda não se encontram bem esclarecidos. ${ }^{27}$

O presente estudo foi um primeiro passo para conhecermos, no cenário da região norte mineira, área endêmica de LV, a sua prevalência entre os doadores de sangue do Hemocentro Regional de Montes Claros - Fundação Hemominas, no período de 16/09/08 a 13/11/08.

Os doadores que participaram da pesquisa foram, em sua maioria, homens jovens e residentes na zona urbana, coincidindo com o perfil geral dos doadores de sangue do Hemocentro.

A prevalência observada de $5,5 \%$, pelo método RIFI, também está compatível com o que tem sido relatado em estudo populacional em Minas Gerais. Moreno, ao testar 1.604 moradores na população geral de Sabará/ MG, encontrou 2,4\% a 5,6\% de prevalência de infecção dependendo do teste sorológico empregado. ${ }^{29,30}$ No Maranhão verificou-se prevalência de infecção de cerca de $19,7 \%$ pelo método ELISA. ${ }^{31}$ Outro estudo realizado no Pará constatou $12,6 \%$ de prevalência da infecção por LV na comunidade ao associar os resultados da intradermorreação de Montenegro e RIFI. ${ }^{32}$

No presente estudo, nenhum dos participantes RIFI positivos apresentou positividade no Kalazar detect ${ }^{\circledR}$. Estudos anteriores apontam para baixa sensibilidade deste exame em indivíduos assintomáticos $;^{29,33}$ segundo Moreno, a sensibilidade verificada em estudo populacional em Sabará/MG foi de $26,3 \% .{ }^{29}$ Nosso trabalho reforça a baixa sensibilidade do Kalazar detect® para estudo em indivíduos assintomáticos. No Brasil, quando aplicado em cães de área endêmica, a sensibilidade foi de $92 \%$ e a especificidade de 99,5\%. Entretanto, o teste não foi capaz de detectar infecções nos animais com título baixo de RIFI (1:40 a 1:320). ${ }^{34}$
Estudo realizado em 2003 com 128 pacientes de Montes Claros/MG e Vitória/ES verificou 90\% de sensibilidade e 100\% de especificidade pelo método Kalazar detect ${ }^{\circledR}$, demonstrando sua acurácia no diagnóstico de indivíduos doentes. ${ }^{35}$ Achado reforçado em pesquisa realizada no Maranhão, Piauí, Bahia e Minas Gerais para validação do teste rápido IT LEISH ${ }^{\circledR}$ que apresentou sensibilidade de $93 \%$ e especificidade de $97 \%$. $^{21}$

O desafio de esclarecer a importância de implementar medidas que previnam a transmissão transfusional da LV e definir quais os melhores métodos a serem empregados merecem pesquisas que constatem os melhores procedimentos no estudo da infecção em assintomáticos.

Dos 23 doadores RIFI positivos neste estudo, dois foram positivos no teste ELISA Chagas. Sabe-se que existe a possibilidade de reações cruzadas da RIFI para Leishmania com vários patógenos, inclusive com chagas, ${ }^{36,37}$ o que poderia explicar a positividade dos exames destes dois participantes. Entretanto, não podemos afastar a possibilidade de associação das duas sorologias positivas. A constatação de que 21 dos positivos na RIFI para LV foram negativos para ELISA Chagas nos permite mencionar que a sorologia para chagas não tem sido suficiente para também detectar a positividade para Leishmania na triagem sorológica de doadores de sangue. Com a melhor performance dos kits utilizados para sorologia de chagas, reduzindo as reações cruzadas, podemos estar deixando de detectar outros patógenos (inclusive a Leishmania) .

O risco de transmissão transfusional da LV não fica esclarecido neste trabalho, pois a simples sorologia positiva não implica a presença da Leishmania viável no sangue periférico, além de não esclarecermos sobre a sua viabilidade após processamento e estocagem dos hemocomponentes. Porém, também não é possível afastar este risco potencial.

Diante deste fato, é de fundamental importância discutir as implicações técnicas e éticas, uma vez que, embora a legislação não determine que a leishmaniose visceral deva ser testada em bancos de sangue, o conhecimento de uma sorologia positiva impõe aos técnicos a exclusão desta bolsa. Mediante a situação atual de expansão da leishmaniose e a ineficácia no controle da doença, cabe questionar e implementar pesquisas que respondam de maneira consistente sobre o potencial risco de transmissão transfusional em áreas endêmicas.

A legislação atual da hemoterapia brasileira ${ }^{17}$ trata de maneira genérica, no item B 5.2.6, sobre as doenças infecciosas transmissíveis pelo sangue e considera inaptos permanentes os candidatos a doação que já tiveram história de LV. Na Fundação Hemominas, além de considerar inapto definitivo o doador com passado ou sintoma da doença, tem sido preconizado na rotina da triagem o exame de palpação abdominal, o que não implica na prevenção da transmissão da doença em indivíduos assintomáticos. 
Estudo na França verificou que a leucodepleção pode ser uma boa medida para evitar a transmissão transfusional da LV. Ao retirar os leucócitos do sangue, estes filtros retêm patógenos intracelulares e, segundo este estudo, parecem eficazes para leishmania. ${ }^{15}$ Os filtros de leucócitos já são utilizados para evitar transmissão do citomegalovírus em pacientes de risco, além de outras indicações clínicas..$^{24,38}$

O impacto na segurança transfusional, nos estoques de sangue e, consequentemente, na saúde dos receptores em áreas endêmicas, deve nortear sempre as estratégias adotadas para evitar os riscos de transmissão de doenças. Não existe definição ou consenso sobre quais as melhores medidas a serem adotadas, nem certeza da significância da transmissão da LV. Testar a filtração do sangue no ato da coleta pode ser uma alternativa, assim como a possibilidade de implementar sorologia em áreas endêmicas, associar sorologia e uso de filtros de leucócitos, eleger populações de maior risco (crianças, imunossuprimidos) para serem beneficiados por medidas de prevenção da LV. Todas estas possíveis medidas merecem maiores discussões, se considerado relevante o risco de transmissão transfusional da doença.

O impacto da sorologia positiva para LV detectada neste estudo, cuja prevalência foi de 5,5\% pelo método RIFI, seria de grande repercussão nos estoques de sangue que abastecem nossa população. Conhecer bem quais os melhores recursos diagnósticos para o estudo de assintomáticos é essencial para assegurarmos triagem adequada sem prejuízo do atendimento, se a necessidade desta medida fosse estabelecida.

Devemos reforçar que a LV é uma doença grave, em que a evolução depende da resposta imunológica individual e que indivíduos imunossuprimidos apresentam maior risco de progressão e gravidade da doença.

A gestão de tantas variáveis, que implicam riscos, inovações, custo e benefício, estoque estratégico, saúde de seres humanos, além das constantes possibilidades de transmissão de várias doenças ainda não conhecidas ou testadas na prática, é o maior estímulo para justificar e intensificar o desenvolvimento de pesquisas em nosso país. O cidadão que, hoje, necessita de transfusão de sangue, merece todo respeito, segurança e qualidade dos produtos e serviços, lembrando que aquele que hoje doa sangue, amanhã poderá vir a precisar deste gesto de desprendimento e solidariedade, capaz de salvar vidas.

\section{Abstract}

tThe objective of this work was to study the prevalence of adults infected by Leishmania (Leishmania) chagasi among blood donors of the Hemominas Foundation in Montes Claros, Brazil. A crosssectional, quantitative epidemiological study was performed of 421 blood donors from September 162008 to November 13 2008. The L. l. chagasi indirect immunofluorescence test (RIFI) was utilized. Donors that presented with positive results in RIFI were retested using the fast immunochromatographic test (Trald). The gender, age, place of origin, number of donations, leishmania and chagas disease serum results were studied with statistical correlations being analyzed utilizing the chi-square test ( $x 2), x 2$ with linear tendency and the Fisher test; a level of significance of $5 \%(p<0.05)$ was considered acceptable. The profile of the study sample was similar to the overall donor profile. The participants were mostly donors from urban areas (92.7\%), living in Montes Claros (67.9\%), men $(61.3 \%)$ and with ages between 18 and 29 years old. In relation to the serum results, $23(5.5 \%)$ were positive according to the RIFI however none of them were positive by the Trald. On comparing the results of RIFI and the chagas disease serum test (Elisa), two individuals were positive for both tests, thereby giving a statistically significant correlation $(p=0.003)$. However the other 21 were positive only by RIFI and negative for chagas disease. The results show the prevalence of infection by L. l. chagasi in asymptomatic, adult blood donors in the Hemominas Foundation in Montes Claros, and highlight the need for further studies on the possible risk of disease transmission via blood transfusion. Rev. Bras. Hematol. Hemoter.

Key-words: Visceral Leishmaniasis; blood donors; asymptomatic.

\section{Referências Bibliográficas}

1. Ministério da Saúde. Fundação Nacional de Saúde. Centro Nacional de Epidemiologia. Leishmaniose Visceral no Brasil: situação atual, principais aspectos epidemiológicos, clínicos e medidas de controle. Boletim Epidemiológico 2001;6:1-11.

2. Gontijo CMF, Melo MN. Leishmaniose visceral no Brasil: quadro atual, desafios e perspectivas. Rev Bras Epidemiol. 2004;7(3): 338-49.

3. Drugs for Neglected Diseases initiative - Leishmaniasis. Disponível em: http://www.dndi.org.br/Portugues/leishmaniose.aspx, dezembro de 2008 .

4. Word Health Organization. Strategic Direction for Research Leishmaniasis. Disponível em: http://www.who.int/tdr/diseases/ leish/direction.htm, dezembro de 2008.

5. Lainson R, Shaw JJ. Evolution, classification and geographical distribution. In: Peters W, Killick-Kendrick R. The Leishmaniasis in Biology and Medicine. Vol. 1. London: Academic Press;1987; p. $1-120$.

6. Pearson RD, Sousa AQ, Jeronimo SMB. Leishmania species: visceral (Kala-azar), cutaneous, and mucosal leishmaniasis. In: Mandell GL, Bennett JE, Dolin R. Principles and Practice of Infectious Diseases. New York: Churchill Livingstone; 2000; p. 2831-45.

7. Michalick MSM. Gênero Leishmania. In: Neves DP, Melo AL, Vitor RWA. Parasitologia Humana. $11^{\text {a }}$ Edição. São Paulo: Atheneu; 2005; p. 41-83.

8. Pearson RD, Sousa AQ. Leishmaniose. In: Ansiello LGD. Tratado de Medicina Interna. 22 ${ }^{\mathrm{a}}$ Edição. Rio de Janeiro: Elsevier; 2005; p. 2184-90.

9. Ministério da Saúde. Leishmaniose Visceral Grave: Normas e Condutas. Secretaria de Vigilância em Saúde, Brasília: Editora do Ministério da Saúde 2006; 60p.

10. Tesh RB. Control of zoonotic visceral leishmaniasis: is it time to change strategies? Am J Trop Med Hyg. 1995;52:287-292.

11. Costa CHN, Vieira JBF. Mudanças no controle da leishmaniose visceral no Brasil. Rev Soc Bras Med Trop. 2001;34: 223-8.

12. Luz KG, Silva VO, Gomes EM, Machado FC, Araujo MA, Fonseca $\mathrm{HE}$, et al. Prevalence of anti-Leishmania donovani antibody among 
Brazilian blood donors and multiply transfused hemodialysis patients. Am J Trop Med Hyg. 1997;57(2):168-71.

13. Fichoux Y, Quaranta JF, Aufeuvre JP, Lelievre A, Marty P, Suffia I, et al. Occurrence of Leishmaniose infantum parasitemia in asymptomatic blood donors living in an area of endemicity in southem France. J Clin Microbiol. 1999;37(6):1953-7.

14. Otero AC, Silva VO, Luz KG, Palatnik M, Pirmez C, Fernandes O, et al. Short report: occurrence of leishmania donovani DNA in donated blood from seroreactive Brazilian blood donors. Am J Trop Med Hyg. 2000;62(1):128-31.

15. Kyriakou DS, Alexandrakis MG, Passam FH, Kourelis TV, Foundouli $\mathrm{P}$, Matalliotakis E, et al. Quick detection of leishmania in peripheral blood by flow cytometry. Is prestorage leucodepletion necessary for leishmaniasis prevention in endemic areas? Rev Transfus Med. 2003;13(2):59-62.

16. Cardo LJ. Leishmania: risk to the blood supply. Rev Transfusion Med. 2006;46(9):1641-5.

17. Agência Nacional de Vigilância Sanitária. RDC 153 de 14/06/04. Brasília; Diário Oficial da União; 2004.

18. Ministério da Saúde. Manual de Vigilância e Controle da Leishmaniose Visceral. Secretaria de Vigilância em Saúde, Brasília: Editora do Ministério da Saúde; 2003; 122p.

19. Secretaria de Vigilância em Saúde. Sinan. Brasília: Ministério da Saúde. Disponível em: http://www.saude.gov.br/sinanweb, outubro de 2008 e janeiro de 2009.

20. Cunha DES. Análise do uso de frações antigênicas de Leishmania sp no diagnóstico imunológico da Leishmania Visceral e diagnóstico imunológico da Leishmaniose Visceral utilizando antígeno recombinante K39 através das técnicas de ELISA e particle gel immunoassay-PAGIA(Diamed). Centro de pesquisas René Rachou, 2001. Monografia para conclusão do programa de vocação científica da Fiocruz.

21. Assis Tália SM, Braga ASC, Pedras MJ, Barral AMP, Siqueira IC, Costa $\mathrm{CHN}$ et al. Validação do teste imunocromatográfico rápido IT-LEISH ${ }^{\circledR}$ para o diagnóstico da leishmaniose visceral humana. Rev Epidemiol Serv Saúde. 2008;17(2):107-16.

22. Sundar S, Rai M. Laboratory diagnosis of visceral Leishmaniasis. Clin Diagn Lab Immunol. 2002;9:951-8.

23. Cliquet MG. Substitutos do Sangue. In: Bordin José O, Langli Junior, Dante M, Covas Dimas T. Hemoterapia Fundamentos e prática. $1^{a}$ edição. São Paulo:Atheneu; 2007; p. 593-9.

24. Ministério da Saúde. Guia para uso de hemocomponentes. Secretaria de Atenção à saúde, Brasília: Editora do Ministério da Saúde; 2008; $140 \mathrm{p}$.

25. Agência Nacional de Vigilância Sanitária. RDC 10 de 23/01/04. Brasília; Diário Oficial da União; 2004.

26. Agência Nacional de Vigilância Sanitária. RDC 129 de 24/05/04. Brasília; Diário Oficial da União; 2004.

27. Proietti ABFC, Lopes MSN, Urias EVR. Outras doenças infecciosas transmissíveis pelo sangue. In: Bordin José O, Langli Junior, Dante M, Covas Dimas T. Hemoterapia Fundamentos e prática. $1^{\mathrm{a}}$ edição. São Paulo:Atheneu; 2007; p. 525-31.

28. Angulo IL. Infecções emergentes de importância transfusional. In: Bordin José O, Langli Junior, Dante M, Covas DT. Hemoterapia Fundamentos e prática. $1^{\text {a }}$ edição. São Paulo: Atheneu; 2007; p.613-8.

29. Moreno EC, Melo MN, Antunes CMF, Lambertucci JR, Serufo JC, Andrade ASR, et al. Diagnóstico da leishmaniose visceral humana assintomática em uma área urbana do Estado de Minas Gerais, usando métodos sorológicos e biologia molecular. Rev Soc Bras Med Trop. 2006; 39(5):421-7.

30. Moreno EC, Melo Maria N, Genaro O, Lambertucci JR, Serufo JC, Andrade ASR, et al. Fatores de risco para infecção por Leishmania chagasi em uma área urbana do Estado de Minas Gerais. Rev Soc Bras Med Trop. 2005;38(6).

31. Nascimento MDSB, Souza EC, Silva LM, Leal PC, Cantanhede $\mathrm{KL}$, Bezerra GFB, et al. Prevalência de infecção por Leishmania chagasi utilizando os métodos de ELISA (rK39 e CRUDE) e intradermorreação de Montenegro em área endêmica do Maranhão, Brasil. Cad Saúde Pública. 2005;21(6):1801-7.

32. Filho MSR, Silveira FT. Epidemiologia, clínica e imunologia da infecção humana por Leishmania (Leishmania) infantum chagasi em área endêmica de leishmaniose visceral no Pará. Rev Para Med. 2007;31(3):7-18.

33. Braz RFS, Nascimento ET, Martins DRA, Wilson ME, Pearson $\mathrm{RD}$, Reed SG, et al. The sensitivity and specificity of Leishmania chagasi recombinant K39 antigen in the diagnosis of american visceral leishmaniasis and in differentiating active from subclinical infection. Am Trop Med Hyg. 2002;67(4):344-8.

34. Genaro O, Costa RT, Silva JCF, Reis AB, Vieira EP, Arias JR, et al. Evaluation of an immunochromatographic assay for the diagnosis for dogs experimentally and naturally infected with Leishmania chagasi in Brazil. Acta Parasitol Turcica 1997; 21 (Supl.1): 93.

35. Guimarães CSF, Moreira LE, Corey R, Dietze R. Performance of recombinant $\mathrm{K} 39$ antigen in the diagnosis of Brazilian visceral leishmaniasis Am J. Trop Med. Hyg. 2003; 68(3):321-4.

36. Abramo C, Fontes CJ, Krettli Au. Cross-reactivity between antibodies in the sera of individuals with leishmaniasis, toxoplasmosis, and Chagas' disease and antigens of the bloodstage forms of Plasmodium falciparum determined by indirect immunofluorescence. Am J Trop Med Hyg. 1995;53(2):202-5.

37. Griemberg G, Ferrarotti NF, Svibel G, Ravelli MR, Taranto NJ, Malchiodi EL, et al. Immunofluorescence assay with Crithidia luciliae for the detection of anti-DNA antibodies. Atypical images and their relationsship with Chagas' disease and leishmaniasis. Medicina (B. Aires). 2006;66(1):3-8.

38. Razouk FH, Reiche EMV. Caracterização, produção e indicação clínica dos principais hemocomponentes. Rev Bras Hematol Hemoter. 2004;26(2):126-34.

Avaliação: Editor e dois revisores externos

Conflito de interesse: sem conflito de interesse

Recebido: 19/12/2008

Aceito após modificações: 23/02/2009 